\title{
Voluntary Reporting of Greenhouse Gases under Section 1605(b) of the Energy Policy Act of 1992
}

\section{General Guidelines}

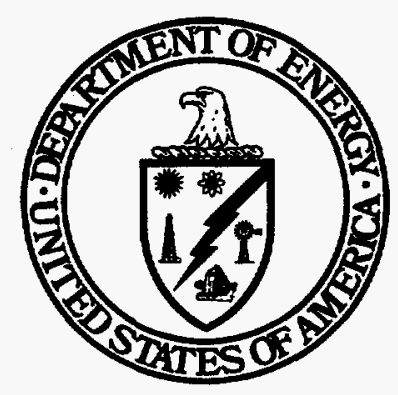

October 1994

United States Department of Energy

Washington, DC 20585

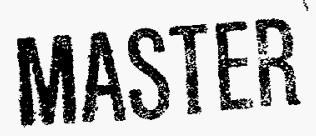

DISTRIBUTION OF THIS DOCUMENT IS UNLIMITED 


\section{DISCLAIMER}

This report was prepared as an account of work sponsored by an agency of the United States Government. Neither the United States Government nor any agency thereof, nor any of their employees, make any warranty, express or implied, or assumes any legal liability or responsibility for the accuracy, completeness, or usefulness of any information, apparatus, product, or process disclosed, or represents that its use would not infringe privately owned rights. Reference herein to any specific commercial product, process, or service by trade name, trademark, manufacturer, or otherwise does not necessarily constitute or imply its endorsement, recommendation, or favoring by the United States Government or any agency thereof. The views and opinions of authors expressed herein do not necessarily state or reflect those of the United States Government or any agency thereof. 


\section{DISCLAIMER}

Portions of this document may be illegible in electronic image products. Images are produced from the best available original document. 


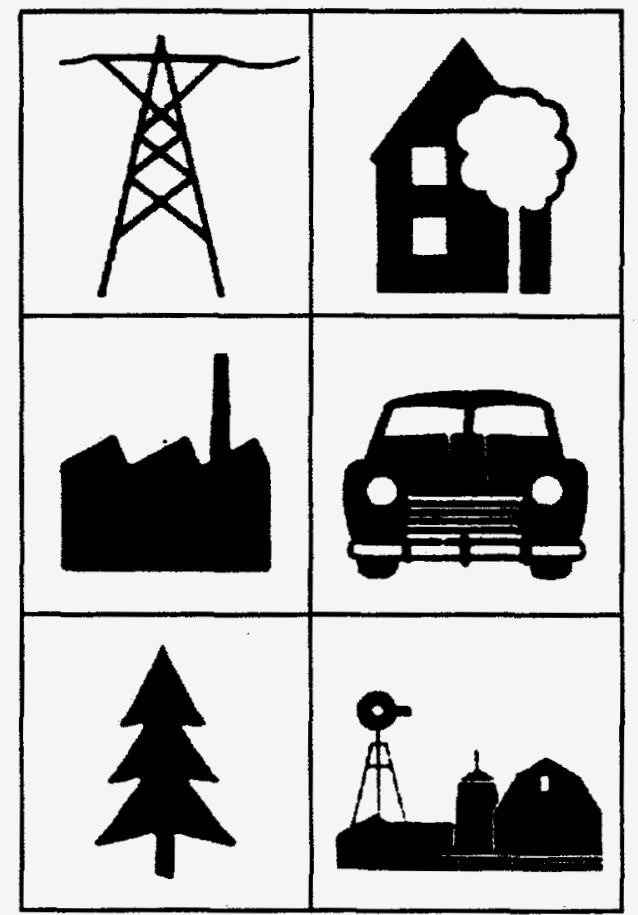

\section{Voluntary Reporting and You}

This program was designed to help you measure and record the actions you take to reduce greenhouse gas emissions or to increase carbon storage in soil or plants. The voluntary reporting program provides an opportunity for you to gain recognition for the good effects of your actions-recognition from your customers, your shareholders, public officials, and the Federal government. Reporting the results of your actions adds to the public groundswell of efforts to deal with the threat of climate change. Reporting can show that you are part of various initiatives under the President's Climate Change Action Plan. Your reports can also record a baseline from which to measure your future actions. Finally, your reports, along with others, can contribute to the growing body of information on cost-effective actions for controlling greenhouse gases.

We've designed this simple, flexible program to encourage you to accurately record your achievements. The program allows you to define activities you choose to report and to determine how you will estimate the effects of those activities on greenhouse gas emissions and carbon sequestration. We recognize that you must balance your efforts to ensure the accuracy of reported data with your goals of keeping costs reasonable in generating the reports.

We are optimistic that the response to this program will show that voluntary programs can do the job. We have been impressed by the level of commitment to the President's initiatives on climate change. This reporting program provides opportunities to report your achievements and to track your progress as you use your ingenuity and creativity in responding to the challenge of climate change. 


\section{General Guidelines}

GG-1 How Are These Guidelines and Supporting Documents Organized? . . . . . . . . 1

GG-2 Why Report Under This Voluntary Reporting Program? . . . . . . . . . . . . 2

GG-3 May I Report and What Should I Report? . . . . . . . . . . . . . . . 3

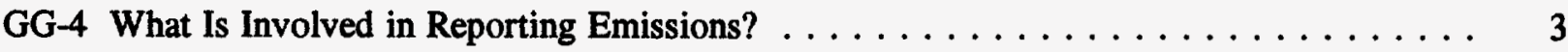

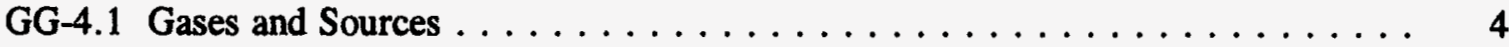

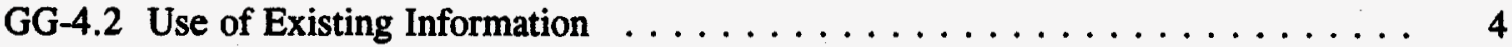

GG-4.3 Scope of Emissions Reporting $\ldots \ldots \ldots \ldots \ldots \ldots$

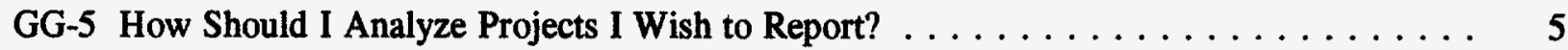

GG-5.1 What Should the Project be Compared To? . . . . . . . . . . . . . 10

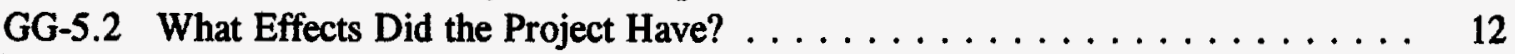

GG-5.3 How Do I Estimate Project Accomplishments? . . . . . . . . . . . . . . 15

GG-5.4 What If Two or More Organizations Wish to Report the Same Project? . . . . 19

GG-5.5 May I Report Through My Trade Associations or Other Third Parties? . . . . 21

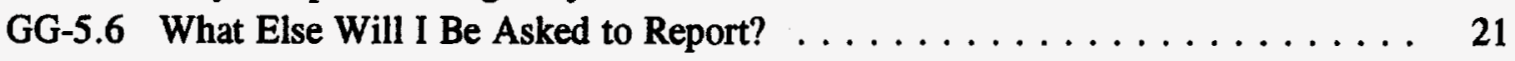

GG-5.7 May I Report International Projects? . . . . . . . . . . . . . . 21

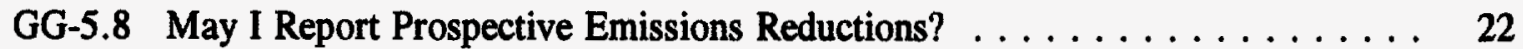

GG-5.9 How Far Back May I Report Projects? . . . . . . . . . . . . . . . 23

GG-5.10 Must I Take into Account the Different Effects of Different Greenhouse

Gases? .......................... 23

GG-5.11 Is It Necessary to Report Emissions Reductions and Carbon

Sequestration Every Year? . . . . . . . . . . . . . . . . . 24

GG-5.12 May I Amend My Previous Years' Reports? . . . . . . . . . . . . . 24

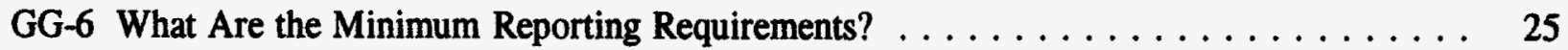

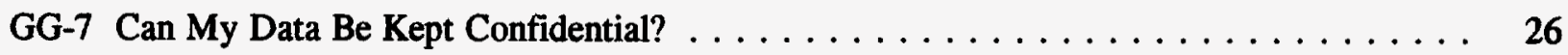

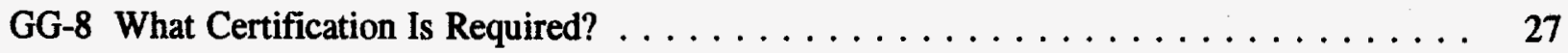

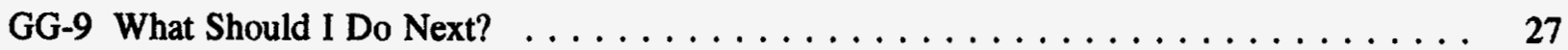




\section{Figures}

GG-1 Careful Project Analysis Requires that you Consider Several

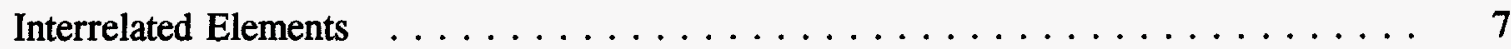

GG-2 Standard Projects Utilize Physical and Default Data $\ldots \ldots \ldots \ldots \ldots \ldots$

GG-3 Reporter-Designed Projects Utilize Your Own Measured or Engineering Data Along with Physical and Default Data $\ldots \ldots \ldots \ldots \ldots \ldots \ldots$

\section{Case Studies}

1. Rarotonga Coconut Cream, Inc. (industrial cogeneration)

Project Description and Emissions Reporting $\ldots \ldots \ldots \ldots \ldots \ldots \ldots \ldots$

Reference Case . . . . . . . . . . . . . . . . . . . . . . . . 12

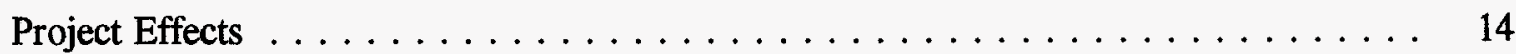

Estimation Methods $\ldots \ldots \ldots \ldots \ldots \ldots \ldots \ldots \ldots \ldots \ldots \ldots \ldots$

2. Rural-Urban Office Managers, Inc. (energy efficiency in buildings)

Project Description and Emissions Reporting . . . . . . . . . . . . . . 9

Reference Case . . . . . . . . . . . . . . . . . . . . . . . 12

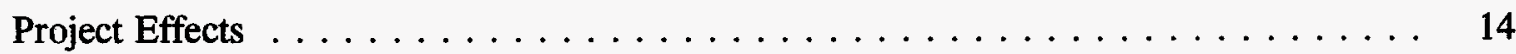

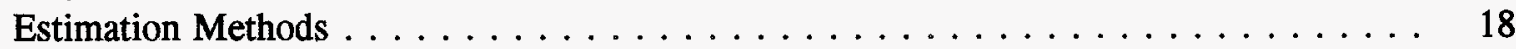

3. Illinois-Ohio Unlimited (new solar-powered electricity generation)

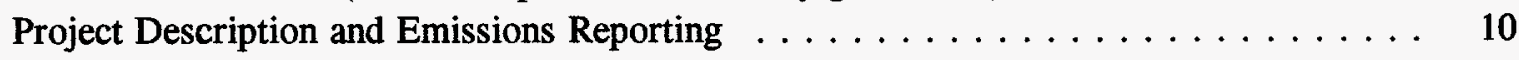

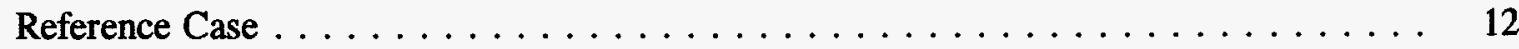

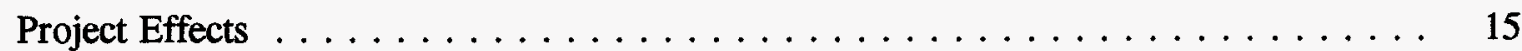

Estimation Methods . . . . . . . . . . . . . . . . . . . . . . . . . . 19

4. Black Forest Cake, Inc. (long-term project reporting) $\ldots \ldots \ldots \ldots \ldots$ 


\section{General Guidelines}

Because of concerns with the growing threat of global climate change from increasing emissions of greenhouse gases, Congress authorized a voluntary program for the public to report achievements in reducing those gases. This document offers guidance on recording historic and current greenhouse gas emissions, emissions reductions, and carbon sequestration. Under the Energy Policy Act (EPAct) of 1992 Section 1605(b) program, reporters will have the opportunity to highlight specific achievements.

If you have taken actions to lessen the greenhouse gas effect, either by decreasing greenhouse gas emissions or by sequestering carbon, the Department of Energy (DOE) encourages you to report your achievements under this program. The program has two related, but distinct parts. First, the program offers you an opportunity to report your annual emissions of greenhouse gases. Second, the program records your specific projects to reduce greenhouse gas emissions and increase carbon sequestration. Although participants in the program are strongly encouraged to submit reports on both, reports on either annual emissions or emissions reductions and carbon sequestration projects will be accepted.

These guidelines and the supporting technical documents outline the rationale for the program and approaches to analyzing emissions and emissions reduction projects. Your annual emissions and emissions reductions achievements will be reported on forms that are available through the Energy Information Administration (EIA) of the Department of Energy, 1000 Independence Avenue, S.W., Washington, DC 20585.

\section{GG-1 How Are These Guidelines and Supporting Documents Organized?}

In these pages, you will find answers to your questions about who may report, what is involved in reporting, and how to develop a credible project analysis to help you accurately report your achievements. The General Guidelines (GG) illustrate the process for analyzing projects using three hypothetical examples (an industrial cogeneration project, an energy efficiency program, and new electricity generating capacity).

You will also find guidance on such issues as joint reporting (if two or more persons or organizations are responsible for achievements), third-party reporting (through a trade association, for example), international projects, confidentiality, certification, and other elements of the reporting process.

For more specific guidance, you may consult one or more of the supporting documents that discuss sector-specific issues and analytic approaches. The supporting documents, organized in two volumes, contain limited examples of project analysis for the relevant sectors. Supporting documents have been developed as follows: 
- Volume I

--Electricity Supply Sector (Part 1)

--Residential and Commercial Buildings Sector (Part 2)

--Industrial Sector (Part 3)

- Volume II

--Transportation Sector (Part 4)

-Forestry Sector (Part 5)

--Agricultural Sector (Part 6).

Each volume includes appendixes that provide conversion tables and default emissions factors (for various fuels and for electricity on a state-by-state basis). You can use these tables and factors for almost any report you submit. The final appendix in each volume presents a list of greenhouse gases for which the Intergovernmental Panel on Climate Change has developed Global Warming Potentials (an index of the relative effects on climate of different gases).

\section{GG-2 Why Report Under This Voluntary Reporting Program?}

If you are undertaking activities to reduce greenhouse gas emissions or to sequester carbon, reporting under this program can be valuable to you and to others. It can be valuable to you because it provides a way to present information about your greenhouse gas-related activities to your customers or constituents who are concerned about the issue of global climate change. It can be valuable to others, including the Federal government (to recognize your achievements under various initiatives), decisionmakers and legislative bodies (to inform the public debate on future greenhouse gas policies), and other individuals or organizations (to learn from each other).

You may wish to report under this program for at least three reasons:

- To Record Emissions and Achievements. You may wish to formally record, in a national database, your greenhouse gas emissions and the results of your activities that reduce or avoid these emissions. Reporting may be part of your participation in programs that recognize your contributions to achieving greenhouse gas emissions goals. These programs include national initiatives such as the Climate Change Action Plan and programs such as Climate Challenge, ClimateWise, and Motor Challenge. However, reporting under this voluntary reporting program is not limited to participants in these programs; you may wish to record the emissions reductions benefits from activities pursued independently of formal recognition programs.

- To Inform the Public Debate. You may wish to provide data which will contribute to more informed public debate on national policy on greenhouse gas reductions. Although a database built upon voluntary reports cannot provide a complete picture of national or sectoral emissions, it could provide credible information on emissions reductions and carbon sequestration projects to evaluate their potential for broader application.

\section{General Guidelines-Page 2}


- To Participate in Educational Exchanges. Data reported under the voluntary reporting program may provide useful information to others seeking ways to reduce their own emissions. New, innovative, and more economical means of reducing or avoiding emissions may be more widely deployed as better information becomes available.

\section{GG-3 May I Report and What Should I Report?}

You may report under this program if you initiate, control, or in some other way participate in activities that (1) contribute to greenhouse gas emissions, (2) result in reducing greenhouse gas emissions, or (3) sequester carbon. The activities may be part of your regular operations, pilot studies, prototype projects, or demonstration projects. They may take place in your community, in your workplace, at a location controlled by a third party, or at a foreign location. You must be a legal U.S. entity, that is, any U.S. citizen or resident alien; any company, organization, or group incorporated under or recognized by U.S. law; or any U.S. Federal, state, or local government entity.

DOE encourages you to submit as comprehensive a report as you can. Elements of a comprehensive report include information about both your emissions levels and your emissions reduction projects. Emissions information could include data on the entire organization and all its greenhouse gas activities, including historic baseline emissions data for 1987 through 1990 , and annual emissions for subsequent years. Comprehensive information about emissions reduction projects could include both emissions reductions and carbon sequestration projects, emissions factors used to determine reductions, assumptions about the project, and data sources. The extent to which you provide information for each of these elements is determined by your assessment of what is necessary for others to clearly understand your project and its effects. Users of the database will be able to gauge the comprehensiveness of your report relative to these elements.

You may report both direct and indirect emissions. As the name implies, direct emissions result directly from fuel combustion or other processes that release greenhouse gases on-site. You produce emissions indirectly when your activities cause emissions to be generated elsewhere. For example, a manufacturer would report as direct emissions the carbon dioxide emitted from the stack of its assembly plant. The same manufacturer could report indirect emissions from the electricity used to light that assembly plant, since the electricity use causes emissions to be generated by an electric utility.

\section{GG-4 What Is Involved in Reporting Emissions?}

Section 1605(b) addresses the reporting of annual emissions as well as emissions reductions and carbon sequestration. You are strongly encouraged, but are not required, to report your greenhouse gas emissions (1) for the baseline period of 1987 to 1990 and (2) for subsequent calendar years on an annual basis. You may wish to report this data for all or as much of your organization as possible, particularly if it would be important to the users of your reports.

General Guidelines-Page 3 


\section{GG-4.1 Gases and Sources}

These guidelines initially provide for reporting four types of greenhouse gases: carbon dioxide, methane, nitrous oxide, and halogenated substances. These are listed below, along with the major activities associated with emissions of these gases. For each gas listed in your emissions report, you should indicate your total emissions; for example, if you report two gases, carbon dioxide and methane, you should report total emissions numbers for both gases.

\begin{tabular}{|l|l|}
\hline \multicolumn{1}{|c|}{ Greenhouse Gases } & \multicolumn{1}{c|}{ Related Activities } \\
\hline carbon dioxide $\left(\mathrm{CO}_{2}\right)$ & $\begin{array}{l}\text { fossil energy combustion } \\
\text { electricity generation and use } \\
\text { industrial processes } \\
\text { forestry and agriculture }\end{array}$ \\
\hline methane $\left(\mathrm{CH}_{4}\right)$ & $\begin{array}{l}\text { landfill operation } \\
\text { coal mining } \\
\text { oil and gas systems } \\
\text { stationary combustion } \\
\text { animal production }\end{array}$ \\
\hline nitrous oxide $\left(\mathrm{N}_{2} \mathrm{O}\right)$ & $\begin{array}{l}\text { stationary combustion } \\
\text { adipic acid production } \\
\text { forestry and agriculture }\end{array}$ \\
\hline $\begin{array}{l}\text { halogenated substances } \\
\text { (for example, } \mathrm{CFCs,} \\
\text { HCFCs, PFCs) }\end{array}$ & $\begin{array}{l}\text { chemical manufacture } \\
\text { use in industrial processes }\end{array}$ \\
\hline
\end{tabular}

The guidelines and supporting documents do not generally discuss other radiatively enhancing gases. However, after the second reporting cycle (that is, after the 1996 cycle), you will be able to report other radiatively enhancing gases, including nitrogen oxides $\left(\mathrm{NO}_{\mathrm{x}}\right)$, nonmethane volatile organic compounds (NMVOCs), and carbon monoxide (CO). In some cases, the supporting documents contain data such as emissions factors for some of these gases. However, in general, you will have to determine how to evaluate your emissions of these gases. Your report must meet the minimum reporting requirements of the program, as described in Section GG-6.

\section{GG-4.2 Use of Existing Information}

Many organizations keep accurate data on projects that involve energy efficiency, fuel switching, conservation, pollution prevention, waste minimization, and/or carbon sequestration. If you keep 
related data for other purposes, reporting greenhouse gas emissions effects under this program will be especially simple and straightforward.

Many potential reporters under EPAct 1605(b) already gather and report emissions information. If you already report similar information (for example, to comply with the Clean Air Act Amendments or under another air quality program) or can easily derive it (for example, from data you submit to regulatory agencies, from smokestack monitoring technologies, or fuel use data kept for internal purposes), you are encouraged to use such information to the extent practical in reporting emissions and emissions reductions under this program. However, you must report the information in a manner that is consistent with these General Guidelines.

\section{GG-4.3 Scope of Emissions Reporting}

You should report on the most comprehensive basis possible to broaden the usefulness of your emissions reports. However, you may define the scope of your emissions reports. In most cases, the needs of your potential audience will dictate the boundaries you draw. If you are able to report emissions for your entire organization, you should consider providing a comprehensive accounting so that your audience can gain a clear understanding of your overall activities. However, reporting total emissions for a single plant or establishment may be more consistent with other elements of your report and may be based on more precise or more readily available data.

Reporting emissions for your entire organization will show the most complete picture of your activities. Entity-level emissions reports can also provide all the data you need to submit reports on emissions reductions at the entity level or can increase the credibility of reports of emissions reductions at an individual project level.

You do not need to report total organization emissions in order to report individual emissions reductions and carbon sequestration projects. In fact, some reporters may not be able to report their organization's or unit's total emissions, because information needed for the baseline years may not be available, or because it is not feasible to estimate their organization's or unit's total emissions even for the current year. Remember, however, that most users of the database will find your reported estimates of emissions reductions more credible if they are accompanied by records of your organization's total emissions for the baseline years 1987 to 1990 and subsequent years.

\section{GG-5 How Should I Analyze Projects I Wish to Report?}

Accurate and credible reporting under this program requires sound project analysis. Rigid rules do not exist for such an analysis, and you may define the emissions reductions and carbon sequestration projects that you report. Your project may consist of all emission-producing activities for your organization; several activities, perhaps as parts of an energy efficiency program; or only one activity, undertaken for its projected cost savings (such as a relighting project) or as a pilot project (for example, an

\section{General Guidelines-Page 5}


experimental industrial process change). Given the broad range of possible types of projects, it is impossible to establish guidance that provides specific rules and appropriate methods for every type of project. The appropriate procedure for project analysis depends on how clearly you can identify the effects of the project, how credibly you can define a basis for comparing greenhouse gas emissions or carbon sequestration with and without the project, and how well you can measure or estimate the effects of your project.

While the guidelines provide you with as much flexibility as possible, every report must

- establish the reference case to use as a basis for comparison with the project

- identify the project's effects

- estimate emissions for the reference case and the project.

Figure GG-1 depicts the overall process of project analysis. Each of these steps is discussed below and in more detail for each sector in the supporting documents. Note that these three elements depend on each other. For example, your choice of a reference case will depend upon both the scope of your project's effects and the data you use to measure or estimate emissions.

In determining the extent of your analysis and reporting effort, you need to match your effort to your purpose for reporting. If you wish to establish a clear record of emissions and emissions reductions, you should perform extensive aralysis and provide for retention of sufficient records to support your report. In any case, you will need to certify the accuracy of the information provided in your report.

These considerations and others in the project analysis process are illustrated in these General Guidelines with three hypothetical case studies: an industrial cogeneration project, an energyefficiency project in a large office building complex, and the purchase of new solar-powered electricity generating equipment. The case studies are intended to be illustrative and by no means address all of the information that may be reported. A basic description of the facts involved in each case follows. These cases will be more fully developed as the discussion of the steps in project analysis proceeds.

These cases are intended to illustrate the range of detail and expense that might be entailed in developing reports of emissions and emissions reductions. The first case involves no emissions reporting and very simple emissions reductions analysis. The second case involves reporting emissions levels for recent years only and moderately detailed emissions reductions analysis. The third example illustrates the most comprehensive report, including emissions reporting for the baseline years 1987 1990 and detailed project analysis. Note that in each case the level of effort and detail reflected in the analysis and report is determined by the reporter's expected audience.

General Guidelines-Page 6 
Apply historic data and/or use projected or modeled data.

Are the effects major or minor?

If major, reconsider project definition.

Use default data or measured/estimated data.
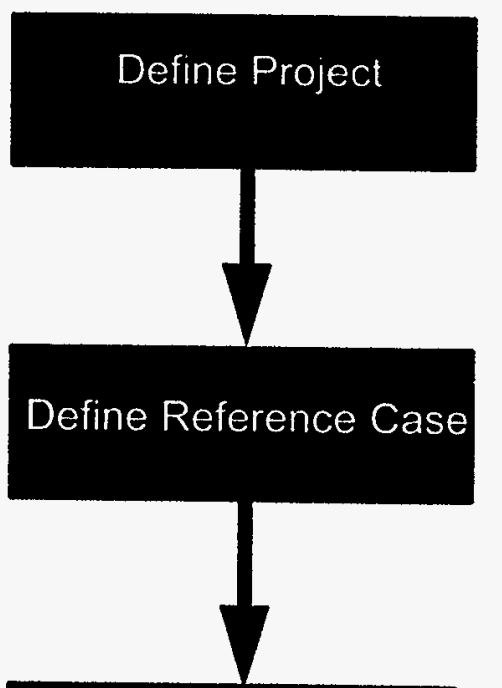

Identify Effects

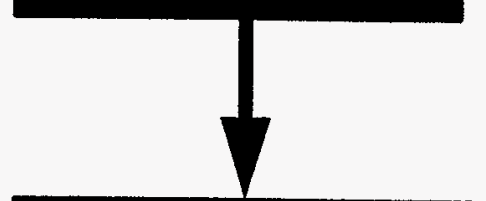

How do I quantify the bottom-
What do I compare the project to?

\section{What effects} did the project have?

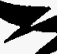
line effects?

What did I do and what should I include in the project?

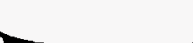

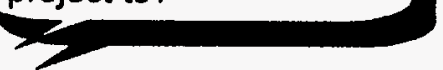

\section{Report Reductions}

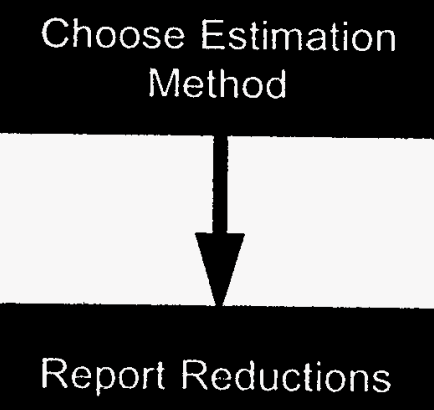

Figure GG-1. Careful Project Analysis Requires that You Consider Several Interrelated Elements. 
Case 1: Rarotonga Coconut Cream, Inc. - Project Description and Emissions Reporting

Note: This example illustrates only one approach to analyzing a project; your analysis, methods, and calculations will vary depending on your particular circumstances, the geographic location of the project, and other factors.

Rarotonga Coconut Cream, Inc. (RCCI) is a small food processing plant in Hawaii. In the past, RCCI purchased its electricity from the local electric utility and produced processing steam from a residual oil-fired boiler. While RCCI's production and energy use have been stable for the past seven years, its energy bills have been growing because of increased electricity rates and oil delivery charges to the company's remote location. Company managers anticipate continued increases in electricity costs as the distribution lines have to be replaced and upgraded over the next five years.

RCCI realized it could cut its energy costs significantly if it installed a cogeneration system to produce its process steam and electricity in a single cogeneration plant fueled by distillate fuel oil. Although the distillate is a higher grade fuel than that currently used, its increased cost is more than offset by the economies realized from the combination of the higher efficiency cogeneration unit and the installation of increased storage capacity, allowing the firm to accept larger, less frequent deliveries. Furthermore, distillate is a cleaner burning fuel oil than residual with lower carbon dioxide emissions per equivalent energy input along with enhanced handling properties. Addition of a backup generator would allow the company to disconnect from the utility transmission and distribution system.

One of RCCI's customers, a grocery wholesaler who was visiting the Rarotonga plant, commented that her company was participating in a Federally sponsored energy-efficiency program and reporting the company's contribution to greenhouse gas emissions reductions through the EPAct Section 1605(b) voluntary reporting program. While RCCI was undertaking its cogeneration project primarily for financial reasons, it was also aware that the project had some beneficial environmental effects, including the reduction of carbon dioxide emissions associated with switching fossil fuel use and electricity production. RCCI decided that, in the interest of sharing its experience with the cogeneration project, the company would report the results to the DOE program.

The first decision RCCI had to make was whether to report its annual emissions of greenhouse gases. As a small business whose primary purpose for participation in the voluntary reporting program was to publicize its experience with using a cogeneration system in a remote location, RCCI was interested in containing its costs of reporting as much as possible. A full entity-wide emissions report would need to account for direct emissions from its oil burner, agricultural operations, and transportation fleet, and indirect emissions from its electricity use. Estimation of emissions from these sources back to 1987 could be costly and time-consuming. RCCI managers decided instead to focus their limited resources solely on an evaluation of emissions reductions associated with their cogeneration project. 
Case 2: Rural-Urban Office Managers, Inc. - Project Description and Emissions Reporting

Note: This example illustrates only one approach to analyzing a project; your analysis, methods, and calculations will vary depending on your particular circumstances, the geographic location of the project, and other factors.

In the late 1970s, Rural Office Managers built a complex of offices just outside the city of Metropolis. By the mid-1990s, the city had expanded, and the offices, originally designed for low-density occupation, were now experiencing higher density occupation.

In response to the change in its physical surroundings, the company reincorporated as Rural-Urban Office Managers, Inc. (RUOMI). Company officials also realized they needed to update their facilities, particularly their heating, ventilating, and air conditioning (HVAC), system and their lighting system to accommodate the change in use. Coincidentally, the energy planner for Metropolis contacted RUOMI to explain that the city had enrolled in a new state initiative called Energy Efficient Cities (EEC) that challenges cities to reduce commercial-sector energy consumption by five percent. RUOMI agreed to participate in EEC.

While the emphasis of the EEC program was on reducing energy use, participants were also encouraged to report the indirect effect that their energy conservation activities had on greenhouse gas emissions, that is, the reduction in greenhouse gas emissions at the generating plant resulting from reduced electricity use at RUOMI's offices. When RUOMI managers explored the DOE voluntary greenhouse gas reporting program, they discovered guidance on how to measure both energy savings and associated greenhouse gas emissions. Therefore, as their contractor designed the HVAC and lighting project, RUOMI made sure that the contractor collected all the data RUOMI needed to submit a report.

RUOMI had not preserved a complete set of its energy bills from the late 1980s. Although this information could have been recovered from the Metropolis energy utility, RUOMI managers decided not to attempt to report the company's historic baseline, entity-wide emissions because the generating mix for Metropolis' electricity supply had changed dramatically since the end of the last decade. However, using the data provided in the DOE guidelines and supporting documents, they were able to derive the direct emissions from natural gas combustion and the indirect emissions associated with electricity use, for the two calendar years just prior to the commencement of their project. RUOMI reported emissions for those two years and for each year thereafter. 
Case 3: Illinois-Ohio Unlimited - Project Description and Emissions Reporting

Note: This example illustrates only one approach to analyzing a project; your analysis, methods, and calculations will vary depending on your particular circumstances, the geographic location of the project, and other factors.

Illinois-Ohio Unlimited (IOU) is an investor-owned utility operating and serving customers in three midwestern states. During a recent integrated resources planning (IRP) effort, it recognized an emerging inability to meet a rising midday peak-load demand, even after pursuing an aggressive peak-shaving, demand-side management program. The IRP identified two alternative responses: purchase additional power from the Indiana Plains Project (IPP), an independent power producer that had excess capacity in its natural gas combined cycle units, or install a large array of photovoltaic cells (PVCs) in southern Illinois and Indiana. PVC electricity production was expected to closely match peak-load demands. While the price of PVCs had decreased dramatically as a result of successful Federal and private research, the second option was still more expensive than the first. However, the public utility commissions (PUCs) in all three of the states in which IOU reported encouraged the utility to install the PVCs. The PUCs reasoned that soon PVCs would be economically competitive and this was IOU's opportunity to gain experience with the technology.

Both IOU and its PUCs were concerned, however, that the utility might be inadvertently penalized if subsequent Federal regulations should mandate reductions of emissions of greenhouse gases but not recognize IOU's early reduction effort. IOU decided to report the PVC projects through DOE's voluntary greenhouse gas reporting program. Because IOU knew that use of its information in connection with the requirements of future policy debates would demand complete and accurate information, it kept careful records, and in each case followed the most rigorous requirements of the voluntary reporting guidelines.

As part of its reporting process, IOU reported its entity-wide greenhouse gas emissions for each of the four baseline years, 1987 to 1990, and for every subsequent calendar year. These reports included estimates of emissions from generating processes, IOU fleet vehicle emissions, and office and building operations.

\section{GG-5.1 What Should the Project Be Compared To?}

A crucial consideration in evaluating your project's accomplishments is how well you can establish a reference case-that is, an emissions level against which to measure the effects of your project. Note that, once you construct your reference case for a project, that reference case should remain constant for the life of the project. If you revise your reference case, you will need to revise any previous project reports to reflect the revised reference case.

A reference case is often referred to as the "but for" scenario, as in, "but for this project, emissions would have been ... ." Two possible ways to finish this sentence are: (1) "... the same as a previous year" (the basic, or historic, reference case) or (2) "... different from any previous year" (the modified reference case, which is adjusted from historic or projected data or based on established standards). Each of these cases is discussed below.

Under this program you may choose between these two approaches. To fulfill your purposes for reporting, you will want your reference case to be clear and understandable. Depending on the nature of and circumstances associated with your operations, a basic reference case (using historic emissions) may provide a suitable benchmark against which to compare project emissions. In other cases, you may determine that a modified reference case is more appropriate. Even if you choose to use a

\section{General Guidelines-Page 10}


modified reference case, you still may wish to provide your historic emissions data to enable users of the EPAct 1605 (b) database to evaluate the reported emissions reductions efforts with respect to a historic baseline.

Basic. The basic reference case uses only historical data. Emissions from the project or sequestration levels may be compared with the corresponding emissions or sequestration level for some previous year(s), for example, (1) the 1987 to 1990 period, the period that EPAct Section 1605(b)(1)(A) describes as the baseline years for purposes of reporting emissions; (2) the year(s) just prior to commencement of the emissions reductions project; or (3) some intervening year(s) more representative of normal operations. The reference case may be defined as the average annual emissions during some multiyear period or the highest or lowest annual emissions during that time. Alternatively, you could choose a single reporting year (for example, 1990) as the reference case year.

Modified. The modified reference case recognizes that even in the absence of your project, your future emissions levels may differ from past levels. The emissions or sequestration levels in the reference case may differ from historical levels because of gradual, predictable changes or because of abrupt changes. Gradual changes in emissions might occur because of growth or decline in industrial output, slowly changing technologies, or natural processes, such as natural regeneration of clear-cut forests. In the case of expanding output or operations, you might extrapolate the reference case from past trends and external data to determine what emissions would have been in the year in which the project's effects are being measured. This process may involve using models and adjusting for growth over time. You could estimate the reference case emissions using historic or current-year data and adjusting for future growth by multiplying the historic emissions rate (emissions per unit of production) by the units produced in the reporting year.

A modified reference case based on a hypothetical, abrupt, external change presents a greater challenge for the reporter. For example, a reference case for a forest preservation project might be built on the assertion, "The forest would have been cut if we had not taken actions to preserve it." If you use this type of reference case, you should take extra care to document the facts underlying the case and to build a sound explanation about why this is the appropriate reference case to use in developing your analysis.

Reference cases for projects involving new operations or added capacity may lie between the two extremes of abrupt changes and gradual changes. For these activities, you will also need to exercise care in constructing a credible modified reference case. Use of industry standards or alternatives actually considered in the planning stages will build credibility. For example, if in the construction of a new building you exceed existing building standards for energy efficiency, you could justifiably assert that the reference case for that project is a building that just meets the standards. 
Case 1: Rarotonga Coconut Cream, Inc. - Reference Case

RCCI decided to use a basic reference case. Managers reasoned that, in the absence of the shift to the distillate oil-fired cogeneration system, they would have continued using the residual oil-fired boiler and purchased electricity. Because its production levels had been constant over the past seven years, RCCI felt no need to modify the historic levels of energy use to reflect expected future trends. Instead, it decided to use an average of its emissions for 1989 and 1990 , the earliest two years for which it had energy use records. Consistent with the RCCI project description, the reference case only incorporated the plant's electrical, processing, and steam production systems.

\section{Case 2: Rural-Urban Office Management, Inc. - Reference Case}

RUOMI chose to use a basic reference case, averaging its emissions for the years 1993 to 1995 . There were several reasons for this decision. Because the use patterns and demands of RUOMI's tenants had changed dramatically from 1980 to 1990 , the years 1987 to 1990 (or an average of these years), would not have been an appropriate indicator of expected emissions in the late 1990s. However, by 1992, RUOMI had established many long-term contracts with its tenants. Energy-use patterns had stabilized, and there was no reason to expect significant shifts in the foreseeable future. The company chose to average the years 1993 to 1995 because the first three months of 1994 included unusually cold weather and were not indicative of general energy demands. While its emissions reductions would have appeared larger if RUOMI had used only 1994 as a reference case, company officials were informed by the Metropolis energy planner that the reports could lose credibility if they only compared their project's energy use and emissions levels to a worst-year reference case.

\section{Case 3: Illinois-Ohio, Unlimited - Reference Case}

IOU's project was clearly driven by increased demands for its product. This immediately suggested that past emissions levels would not be a good model of what would have been, but for the project. Therefore, the utility chose to use a modified reference case to reflect the growth in peaking demand it was experiencing. However, IOU also recognized that it was operating in an environment where a company's current emissions are often compared to some historic level. Therefore, IOU decided to report both historic 1987 to 1990 emissions levels, and the modified reference case reflecting its changing customer demands.

\section{GG-5.2 What Effects Did the Project Have?}

The second major step in project analysis is identifying effects of the project. Your report should address all the effects that you can identify-not just the obvious, intended effects, but also less noticeable, unintended effects. Effects you should consider include activity shifting (moving processes within your organization), outsourcing (purchasing commodities or services you formerly produced), life cycle emissions shifting (upstream and downstream changes in processes or materials used), and market effects (offsets to achievements caused by residual demand).

Example: An electricity conservation project reduces electricity use at an industrial site and associated carbon dioxide emissions at the utility. However, the utility's emissions of other greenhouse gases, such as methane and nitrous oxide, will be reduced as well. In addition,

\section{General Guidelines-Page 12}


conserving electricity may lead to other effects within the utility's transmission and distribution system. All of these effects should be identified (and quantified, where possible).

Example: Closing an industrial plant will likely reduce on-site emissions. However, if another plant is opened or expanded to meet market demand for the former plant's products, the increase in emissions from the new plant would at least partially offset the decrease in emissions resulting from the closing. To place the overall effects of the closing in context, emissions associated with the replacement production capacity should be identified and quantified to the extent possible.

Example: Shifting an activity to another part of your organization or substituting your production of a commodity with its purchase from others may appear to reduce your emissions.

Manufacturing a component at a subsidiary's plant, or the purchase of power by a utility for distribution to customers, however, are some examples in which net emissions may not have changed. The emissions associated with the shifted or substitute production activity should be taken into account, regardless of where it occurs.

Example: Manufacturers can switch from steel to aluminum and claim reductions because working with aluminum results in fewer emissions. However, the production of the aluminum itself creates emissions different from those associated with the production of the steel. Both the on-site changes and the upstream changes should be considered when you analyze whether you have emissions reductions to report under this voluntary reporting program.

Example: Extending the rotation length or completely precluding harvesting at a given forest location increases the carbon storage services at that site. However, the added sequestration may be largely offset if another site is harvested earlier than it otherwise would have been to meet the market demand for timber that was not met by timber from the first site.

Effects you can identify should be reported. These would include any on-site effects resulting from changes in both fuel combustion and electricity use. Off-site effects may be more problematic. In some situations, you may have relationships with customers or suppliers that allow you to both identify and estimate effects that occur outside your organization. If you have or can get such information, you should report it. Effects you can identify but have no data for should be so noted in your report.

Although quantifying all effects of a project can be difficult, keep in mind that the credibility of your report will depend to some extent on your ability to identify effects. If your targeted audiences can easily identify effects that you have ignored in your analysis, the credibility of the entire report may be in question. 


\section{Case 1: Rarotonga Coconut Cream, Inc. - Project Effects}

It was easy to identify the obvious effects of the cogeneration project: the reduction of direct emissions as a result of switching from residual oil to distillate as the primary on-site fuel and the reduction of indirect emissions associated with reduced production of electricity by the electric utility. However, after giving the matter some additional thought, RCCI realized that other effects were associated with the project as well. For example, the number of fuel delivery vehicle trips was reduced by half with the switch from residual oil to distillate and the increased storage capacity. Line losses and the indirect emissions associated with the very long distribution of low voltage electricity were deemed to be negligible and beyond RCCl's ability to calculate.

RCCI listed each of the effects it could identify, but decided not to attempt to quantify any but the first two effects.

Contribution to
Project Effects

Significance

\begin{tabular}{lll}
\hline $\begin{array}{l}\text { Reduce emissions associated with utility electricity } \\
\text { production }\end{array}$ & + & Large \\
$\begin{array}{l}\text { Reduce } \mathrm{CO}_{2} \text { emissions associated with on-site fossil } \\
\text { fuel burning (switching from residual to distillate) }\end{array}$ & + & Medium \\
$\begin{array}{l}\text { Reduce transportation-related services } \\
\begin{array}{l}\text { Decrease indirect emissions associated with line } \\
\text { losses }\end{array}\end{array}$ & + & Small-Medium \\
\hline
\end{tabular}

\section{Case 2: Rural-Urban Office Management, Inc. - Project Effects}

RUOMI contracted with Environmental Security Consulting Organization (ESCO), a local energy service company, to evaluate the costs and benefits of several alternative technologies. After careful evaluation of the use patterns and tenant needs in RUOMI's office complex, ESCO provided a list of two dozen potential energy efficiency improvements and the energy savings and costs associated with each. They explained to RUOMI's management, however, that simply summing across all technologies would not provide an accurate assessment of expected energy savings. Many of the equipment changes would interact with each other, some having negative effects on energy savings, others having synergistic effects. Further, the type and extent of the interactions would depend upon actual use patterns as well as seasonal variations and weather patterns. Following ESCO's recommendation, RUOMI contracted for 14 of the items on the list.

Because of the complex nature of the energy changes expected from the modifications, ESCO recommended that the resulting effects of the activities be analyzed as one integrated project. This avoided the difficulty of having to sort out the impact of each equipment change. It also made any evaluation for the DOE voluntary reporting program simpler. Since RUOMI was analyzing the projects at the entity level, emissions reductions could be calculated directly from its emissions report. Therefore, separate identification of each project's effects was unnecessary. 
Case 3: Illinois-Ohio Unlimited - Project Effects

Identifying all of the effects of IOU's project and reference cases was not a simple exercise. IOU recognized that it needed to consider the effects that its project had (1) on its own operations and emissions, (2) on the emissions of IPP, (3) possibly on the operations of the larger regional power pool, and (4) on the supplier of the PVCs. It was not sure it could accurately estimate all of these effects without incurring unreasonable analysis costs, but it at least wanted to identify them in planning the analysis that would lead to its completed report.

\begin{tabular}{lcc}
\multicolumn{1}{c}{ Project Effects } & $\begin{array}{c}\text { Contribution to } \\
\text { Reduction }\end{array}$ & Significance \\
\hline $\begin{array}{l}\text { IPP emissions that would have gone up because of } \\
\text { additional power purchases are reduced }\end{array}$ & + & Large \\
PVC manufacturer emissions do go up & - & Small \\
Power pool emissions might change & $?$ & Unknown \\
IOU emissions do go down & + & Small \\
\hline
\end{tabular}

\section{GG-5.3 How Do I Estimate Project Accomplishments?}

The final major step in project analysis is estimating emissions levels for both the reference case and project case to determine emissions reductions. The guidelines and supporting documents provide you with a wide range of options for obtaining data and defining the methods for estimating your project's effect on greenhouse gas emissions and carbon sequestration.

First, the guidelines and supporting documents recognize three categories of data.

Physical data. This is information that describes the activities involved in your project. For example, how many exit lights were replaced? What was the power requirement of the old and the new lights? How many hectares of trees were planted? What species of trees? How many trees per hectare?

Default data. This is information provided by the supporting documents to assist you in evaluating the emissions or sequestration effects of your project. Using default data increases your ease of reporting (in some cases, allowing you to report when you might not otherwise have enough data). However, using default data may decrease precision and, because the defaults may be conservative, your emissions reductions may appear lower than they actually are. There are two categories of default data:

Emissions factors. These are factors that allow you to convert information about a change in energy use to an estimated change in greenhouse gas emissions. Some emissions factors are rather precise. For example, the change in direct emissions of carbon dioxide from a reduction in methane combustion is essentially constant, regardless of when or where the change took place. Other emissions factors, and particularly those for indirect emissions, are less precise.

\section{General Guidelines-Page 15}


For example, the supporting documents provide emissions factors for electricity on a state-bystate basis. However, the effect that a change in electricity consumption has on emissions will vary by location within the state, the time of day, and the season that a change occurs.

Stipulated factors. These are factors that allow you to convert physical data about your project into estimates of changes in energy use, greenhouse gas emissions or carbon sequestration. The guidelines provide this information for a few types of projects where the scope and nature of the project can be clearly defined and where the effects on emissions can be predicted with relative certainty. For example, the supporting document for the forestry sector provides stipulated factors for converting physical data about tree planting into estimates of carbon sequestration. The supporting document for the residential and commercial buildings sector provides stipulated factors for converting information about certain energy-efficiency projects into estimates of fuel savings. These estimates can be combined with default emissions factors to estimate reductions in greenhouse gas emissions.

Reporter-generated data. This is information that you provide which is used to estimate the effects of your project. There are two categories of reporter-generated data:

Measured data. These are data, collected directly from the project or a control group, that you use to estimate your project's accomplishments.

Engineering data. These are data that you derive from various sources, such as engineering manuals, manufacturer's equipment specifications, surveys, academic literature, professional judgment, and computer models.

Based on these three categories of data, the guidelines and supporting documents recognize two categories of projects: standard projects, which rely on physical and default data, and reporterdesigned projects, which use measured or engineering data that you develop (as well as appropriate default data). You will need to report the category(ies) of data and projects that you choose to use.

Standard projects. These are projects for which the guidelines and supporting documents provide the procedures and information to estimate the emissions reductions or carbon sequestration. Reports of these projects rely entirely on physical and default data (see Figure GG-2).

Not all projects can be described in standard project reports. The supporting documents for each sector delineate, where possible, projects for which emissions factors and stipulated factors are provided, and for which standard project reports can be submitted. You should recognize that default values are often conservative; that is, if you use them, you are likely to underreport your emissions reductions or carbon sequestration. However, if you do not directly measure and monitor or your organization does not have expertise in estimation methods, the default values will allow you to calculate the effects of your activities. 


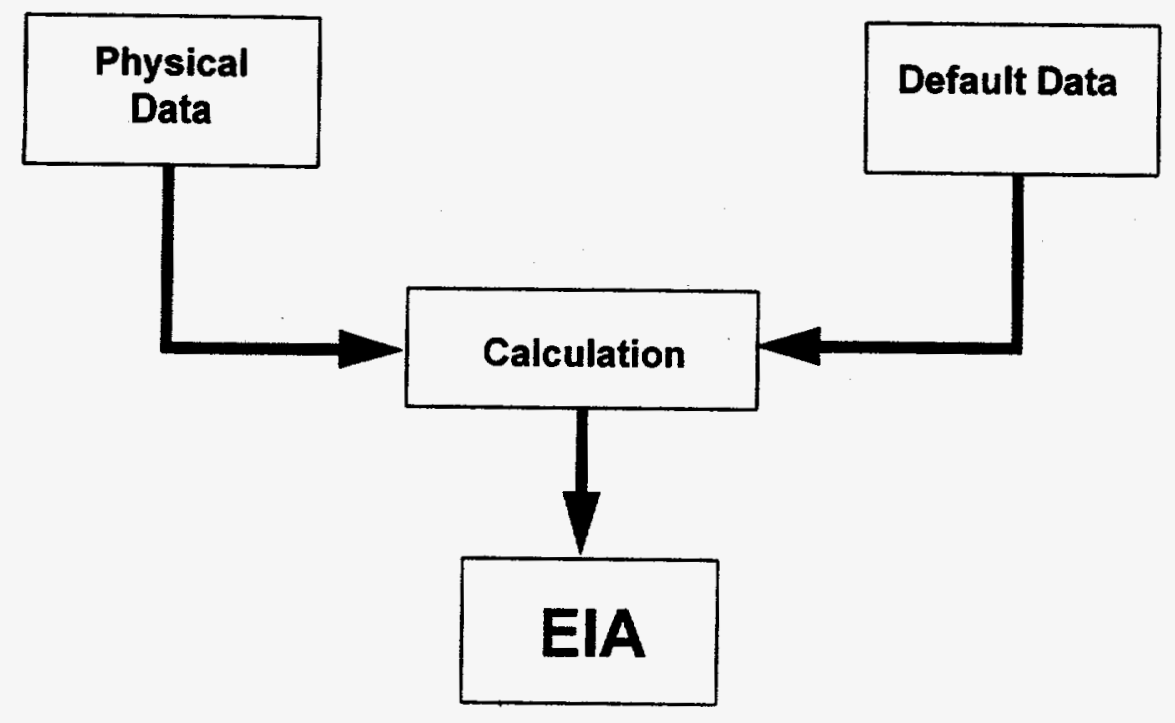

Figure GG-2. Standard Projects Utilize Physical and Default Data.

Reporter-designed projects. These projects use physical and reporter-generated data, possibly in combination with default data, to estimate their accomplishments (see Figure GG-3). For this type of project, you should be able to indicate the source of all data, and in the case of data you generate, how it was measured or derived. For reporter-designed projects, the supporting documents for each sector provide principles and guidance.

Estimation of the emissions effects of many reporter-designed projects will require that you not only gather measured or estimated data, but that you also manipulate this information to derive the emissions levels of your project and reference case. The data manipulation could involve relatively simple calculations or extremely complex modeling. You should be able to identify the nature of the calculations and/or the type/name of the model you have used. In some instances, it may not be possible to estimate emissions for both the project and the reference case. In these cases, identified in the supporting documents for each sector, you may need to measure the emissions reductions directly.

Finally, the emissions reductions or carbon sequestration of your project is simply the difference between your project emissions/sequestration and your reference case emissions/sequestration. 


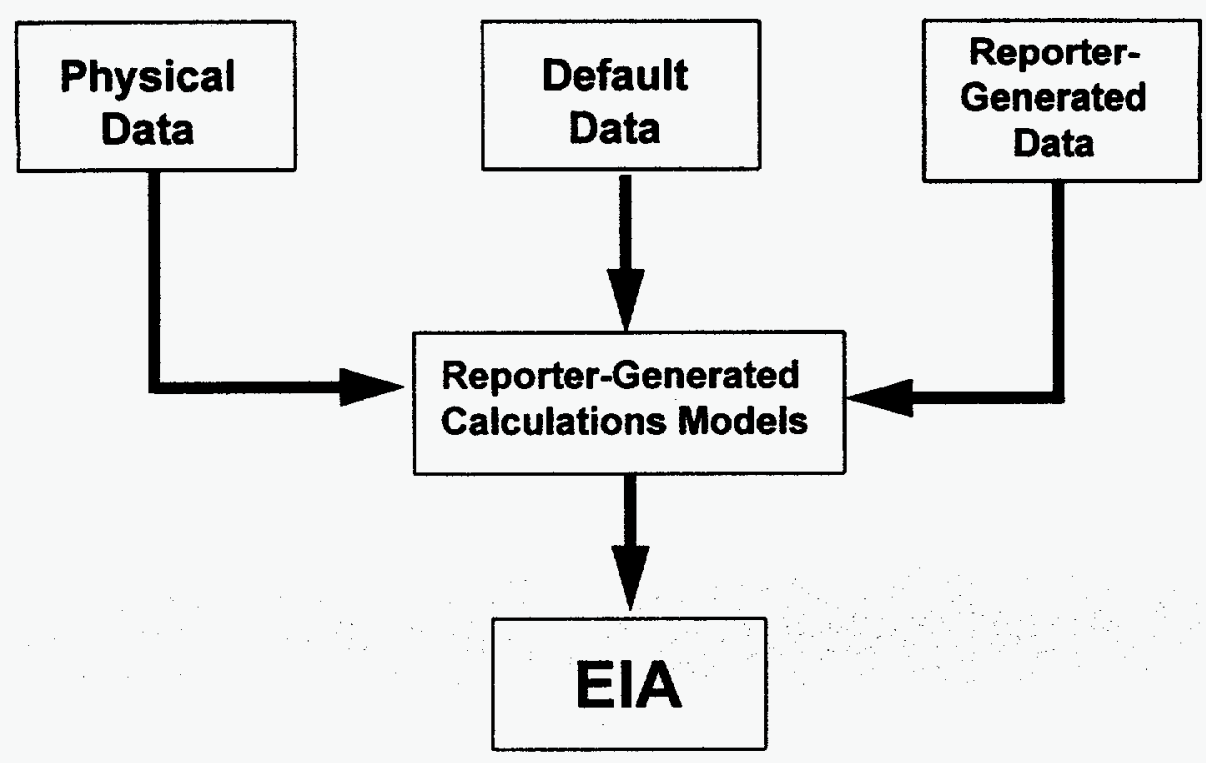

Figure GG-3. Reporter-Designed Projects Utilize Your Own Measured or Engineering Data Along with Physical and Default Data.

Case 1: Rarotonga Coconut Cream, Inc. - Estimation Methods

RCCI limited its quantitative analysis to the obvious effects; estimation of the annual emissions reductions associated with its project was simple. First, it estimated the annual emissions associated with the project. This was simply its annual distillate oil consumption multiplied by the default emissions factor for distillate oil supplied by the guidelines' supporting documents. Second, for the reference case, RCCI multiplied its reference case annual electricity use by the default electricity emissions factor for its state, multiplied its reference case annual residual oil use by the default residual oil emissions factor, and summed the two to arrive at total emissions for the reference case. Its total reported emissions reductions were the difference between the reference case emissions and the project case emissions.

RCCI was pleased that it was able to do its entire analysis based on data it had readily at hand, that is, its fuel and electricity use records from before and after the project, and the default emissions factors provided by the guidelines.

\section{Case 2: Rural-Urban Office Managers, Inc. - Estimation Methods}

ESCO, the contractor for RUOMI, had primary responsibility for preparing the voluntary report for the DOE program. ESCO knew that because of the complexity of the project it could not derive estimates using default data provided in the Guidelines' supporting documents. The project managers turned to the supporting document for the residential and commercial buildings sector to identify the recommended methods for gatbering data for their type of project. They found that the recommended methods included approaches very similar to ones they had previously used to measure energy savings in complex projects. After a full year of measuring and monitoring, they summarized the energy-use data, and performed calculations to derive the difference between the project energy use and the reference case energy use.

Applying the natural gas and electricity emissions factors supplied as default data, they converted the estimated energy reductions to estimated emissions reductions. 
Case 3: Illinois Ohio Unlimited: Estimation Method

IOU recognized two distinct parts to its emissions reductions estimation process. First, it needed to evaluate the direct electricity system emissions for both its reference case and project case. Second, it wanted to estimate the emissions associated with manufacturing the PVCs. Tackling this latter point first, IOU contacted a prospective PVC supplier for any information on emissions associated with the PVC manufacturing process. The supplier, it turned out, had commissioned a report that estimated not only the direct carbon dioxide emissions associated with the manufacture of PVCs, but also the emissions associated with the supply of raw materials-steel, aluminum, chemicals, and electricity-that were used in PVC fabrication. Had this information not been available, IOU would have had to decide whether or carry out this study itself or not quantify this effect at all, possibly affecting the credibility of its project report.

IOU then turned to the electricity system emissions effects of its project. The project reduced emissions that would have occurred had IOU purchased its electricity from IPP. Additional production from IPP for daytime peaking would have been generated by a natural gas combined cycle unit. IOU developed a single conversion factor for the emissions per $\mathrm{kWh}$ that would have occurred for electricity from IPP's system. This meant that as the peak daytime demand grew over time, IOU would be able to estimate that portion of the emissions for the reference case that was attributable to IPP, that is, how much higher IPP emissions would have been had IOU relied on purchased power.

The new PVC system was designed to meet the growth in demand over the next decade. But because the PVCs would be generating at full capacity immediately, they would actually displace some of IOU's current daytime generating capacity. The marginal unit in IOU's generation equipment was an oil-fired turbine generator. IOU developed a conversion factor for the emissions per $\mathrm{kWh}$ that would have occurred from that unit, if its production had not been partially displaced by the solar power system.

In summary, the IOU emissions reductions estimation consisted of three major components. First, at the start of the project there was an initial emission of carbon associated with the production of the PVC units. This effect was reflected only in the first annual report. While some of these emissions had actually taken place as many as two years earlier, IOU believed it was sufficiently realistic to account them all to the first reporting year. Second, the project emissions also showed a sudden drop in emissions for the oil-fired plant due to displacement of daytime oil-fired generation by the PVCs, whose entire capacity was not initially required to meet midday peak demand. However, as expected, the emissions from the oil-fired plant climbed each year as daytime peak demand grew and increasingly the PVC capacity was used to meet that demand. This increase was reflected in IOU's annual reports. Third, under the reference case, IOU reported constant emissions from its own oil-fired plant and annually increasing emissions from IPP's natural gas combined cycle plant. The emissions reduction each year was calculated by subtracting the project emissions from the reference case emissions.

\section{GG-5.4 What If Two or More Organizations Wish to Report the Same Project?}

You may report activities undertaken in association with others. If you do so, you must identify other potential reporters of the same activity so that the program can account for multiple reports of the same activities. You may wish to make arrangements for reporting with others involved in your project.

Joint activities generally fall into one of two categories. The first category includes one-time transactions that are large enough to require negotiation before the exchange takes place and generally involve a written contract, such as demand-side management (DSM) programs. The second category comprises transactions that take place repeatedly between manufacturers and consumers where negotiated contracts are generally not involved, such as individual purchases of household appliances.

\section{General Guidelines-Page 19}




\section{Three Examples of Joint Activities}

Demand-side management programs: When an electric utility undertakes a DSM program, three parties are involved in reducing carbon dioxide emissions: (1) manufacturers of the energy-efficient equipment, such as improved lighting, refrigeration, and other energy-consuming goods; (2) consumers of electricity (households, commercial operations, and industrial firms); and (3) the utility itself. All three parties may wish to report the reductions in emissions.

High-efficiency automobiles: EPAct Section 1605(b) also suggests that the manufacture of highefficiency automobile fleets be reportable under this program. On the one hand, the purchaser of a high-efficiency car makes the ultimate decision to reduce emissions related to personal transportation. On the other hand, the automobile manufacturers who shifted their fleet composition are enabling the automobile owners to obtain more efficient automobiles.

Tree-planting agreements: Some utilities have entered into agreements with landowners to plant trees. The utilities provide funding for establishing the trees; in return the landowners agree to leave the new trees in place for a specified number of years. Both landowners and utilities have played essential roles in carbon sequestration.

Where contracts are involved, you may make arrangements to assign the ability to report resulting emissions reductions before they are reported under this program. You are not required to do this sorting out before you report, but, depending upon how you believe this information will be used, you may wish to resolve any questions before reporting.

You may also wish to mutually decide reporting capabilities for purchases. If you can most easily aggregate many small reports, for example, as a manufacturer of high-efficiency automobiles or efficient appliances, you may wish to include, as part of the purchase transaction, an agreement with the consumer that you will report the energy-efficiency information, unless consumers notify you that they wish to do so.

However, for some technologies, consumers are in a better position to estimate actual accomplishments. For example, new automobile owners can better estimate annual vehicle miles traveled and, hence, the fuel and emissions savings associated with the purchase of a high-efficiency car. You need to consider the trade-off between the ease of reporting and accuracy of estimating the emissions reductions when deciding who will report the reduction-the manufacturer, the automobile owner, or both. If parties report separately, each should identify the other as potential reporters of the same information. 


\section{GG-5.5 May I Report Through My Trade Association or Other Third Parties?}

You may wish to explore reporting through another party-for example, through a trade association, civic association, or fraternal organization. Each of the supporting documents discusses third-party reporting as it may apply to particular sectors.

Third-party reporting may be appropriate for a number of reasons. Organizations may be able to provide technical or administrative assistance to you in reporting. Multiple reports may be aggregated to provide a quantity of emissions and reductions which each individual reporter would not choose to report. Furthermore, confidentiality of some data reported may be enhanced by third party reporting.

Third-party reporting may not be appropriate for your purpose in reporting. For example, it does not provide the transparent link to you that is necessary for creating a formal public record of your emissions and achievements for any purpose.

\section{GG-5.6 What Else Will I Be Asked to Report?}

As part of your report, you will be asked to choose one of three descriptors of the project(s) whose effects you are reporting. This identification will be limited to those provided in the language in EPAct 1605(b): (1) voluntary reductions, (2) plant or facility closing, and (3) state or Federal requirements.

Projects may be undertaken for other purposes, for more than one purpose, or may have greenhouse gas impacts that were not the reason for implementing the project. You may wish to, but will not be required to, report more detailed information on why you undertook the project.

\section{GG-5.7 May I Report International Projects?}

Considerable interest has been generated regarding the potential for cooperation among parties in different countries. For example, there may be opportunities for U.S. parties to reduce greenhouse gas emissions and increase carbon sequestration outside the United States, perhaps at lower cost than possible through domestic activities.

Under this program, you may report the relevant results of your activities outside the United States, under the same process applicable to similar domestic activities. Note that you may have special difficulty in analyzing international activities: determining an appropriate reference case, defining project boundaries, selecting appropriate measurement or estimation methods, and obtaining credible data. Special attention should be given to all the identifiable effects of your international activities.

Under the United Nations Framework Convention on Climate Change, nations that are parties to the Convention will determine how cooperative efforts between member nations and their respective citizens ("joint implementation") will be counted toward meeting each country's commitments under 
that treaty. The President's Climate Change Action Plan, announced in October 1993, includes a pilot program called the United States Initiative on Joint Implementation (USIJI) designed to help establish an empirical basis for considering approaches to joint implementation. The USIJI program has developed evaluation criteria and will develop emissions measurement and verification methods for international projects accepted into the pilot program.

If you are reporting the results of any international project to this program, you will also indicate whether it has been accepted under the USIJI or under the Convention as an accountable joint implementation project. Reporting the results of an international activity under the EPAct 1605(b) program alone does not bring it under the umbrella of formal joint implementation.

\section{GG-5.8 May I Report Prospective Emissions Reductions?}

Many projects that reduce greenhouse gas emissions or sequester carbon achieve their results over several years, or even decades. For some of these projects, the accomplishments are evaluated by means of computer modeling or engineering estimates, rather than by direct measurement and monitoring of greenhouse gas emissions and flows. In those cases, the estimation process is generally carried out before the project begins.

If you have analyzed your project using a method that estimates effects prospectively, you may choose in the first reporting year to report the expected annual emissions reductions or carbon sequestration for future years. However, that information will be maintained separately from the EPAct 1605(b) database.

To have your project accomplishments recorded in the EPAct 1605(b) database, you must certify each year that the project continues to perform as expected. As you certify each year's accomplishments, EIA will transfer the data from the database of prospective accomplishments to the EPAct 1605(b) database.

You may also modify your estimates of past accomplishments at any time for any of several reasons. For example, if events following the commencement of the project are different than expected, you may wish to modify your model to more closely reflect actual events. Alternatively, you may simply find modeling or engineering estimation methods that you believe to be more accurate than those you initially employed. You may even decide to carry out field measurements where you had not initially anticipated doing so. Whatever your reason, you can modify the existing estimates to reflect your more accurate estimates of both your past accomplishments recorded in the EPAct 1605(b) database and your expected accomplishments recorded in the database of prospective accomplishments. However, you should provide clear documentation of how you derived the revised estimate. 


\section{GG-5.9 How Far Back May I Report Projects?}

A primary purpose of the program is to record emissions reductions, not to track when projects were initiated. Therefore, you may report new or ongoing projects that have achieved reductions beginning January 1,1991 . However, for any project, you must establish a credible reference case and retain that reference case for all your reports of that project. If you use historic data to construct your reference case, you should not use data earlier than 1987. If you change your reference case, you must amend any previous reports for that project to account for the amended reference case.

Example: You initiated a project in 1991 that reduced emissions from their 1990 levels. This project is reportable.

Example: You initiated a project earlier than 1987 that has decreased emissions every year relative to each previous year. You may establish either a basic or modified reference case based on what emissions would have been without the project (using only data from 1987 on), then report the emissions reductions from the project for 1991 and subsequent years.

Example: You initiated a project earlier than 1987 that reduced emissions to a level that stabilized during (or before) the baseline years 1987-1990. This project would not be reportable, since the reductions were achieved prior to the period covered by the EPAct 1605 (b) reporting program.

Example: You have an ongoing DSM program to encourage replacement of appliances or equipment. You would not be able to report achievements before 1991, but any appliances replaced in 1991 or after that year are new reductions and could be reported.

Example: You have been installing windmills every year for 10 years. In order to report emissions reductions for 1991, you would need to demonstrate that the 1991 windmill displaced emissions-producing generation. If the windmill replaced another, the project would not be reportable.

These are relatively straightforward examples when you construct historic reference cases. Your analysis becomes more complex when you wish to construct modified reference cases. In general, you should not use data from years before 1987 except as additional support for your assertion of what modified levels would have been after 1987.

\section{GG-5.10 Must I Take into Account the Different Effects of Different Greenhouse Gases?}

Your reports on emissions and emission reductions will include data on greenhouse gases in tons of each gas emitted; you will not be required to calculate the various effects of different gases on climate for this voluntary reporting program. However, you may wish to perform these calculations for your own purposes. For example, you may wish to evaluate the costs of competing proposed projects in 
terms of the beneficial effects on climate; in order to do so, you may wish to look at these effects using a common index, such as the equivalent effect in tons of carbon dioxide. You may wish to talk about such equivalencies with various stakeholders or for public relations purposes.

The Intergovernmental Panel on Climate Change has developed an index that compares the impact that each gas has on global warming relative to the effect that carbon dioxide has. Information about this index, called the Global Warming Potential (GWP), is presented in Appendix E, along with GWPs for the types of gases covered by this reporting program. If you wish to use the index, remember that it does not take into account some complexities of atmospheric chemistry and that the underlying science is evolving.

\title{
GG-5.11 Is It Necessary to Report Emissions Reductions and Carbon Sequestration Every Year?
}

This is a voluntary reporting program. You are under no legal obligation to continue reporting. However, you should recognize that the usefulness of your initial reports may be affected by your participation in the program in subsequent years.

If you report emissions reductions for a period of time, and then fail to report thereafter, the user of the database is likely to assume that your project is no longer reducing emissions relative to the reference case. However, this does not negate the value of the reductions accomplished while the project was in place.

Reporting carbon sequestration projects raises a different type of problem. If you report carbon capture for a number of years and then cease reporting, a database user is apt to assume that the carbon that had been captured has been released back to the atmosphere. This not only limits recognition of any accomplishments that may have occurred following cessation of your reports, but largely negates the value of accomplishments already reported.

You or your firm may find that, following successfully reporting to the voluntary reporting program for several years, you miss one or more years of reporting. If you choose to resume reporting, your initial report should contain information not only for the most recent reporting year, but also, if possible, for all of the intervening years during which you did not report. This will ensure that the EPAct 1605(b) database reflects a continuous record of your activities, thereby increasing the credibility of all your reports.

\section{GG-5.12 May I Amend My Previous Years' Reports?}

If you have submitted reports under this program but afterwards develop better data (for example through field measurements or utility-specific emissions factors), or better estimation methods (for example, your organization's adoption of standard analytic procedures), you may amend your previous

\author{
General Guidelines-Page 24
}


reports. You may also need to amend reports because you have amended your reference case for a particular project. Your amended reports should clearly state your reasons for amendment and the bottom-line difference that results from the amendment. The following case study discusses an instance in which a reporter chose to amend previous reports.

\title{
Case 4: Black Forest Cake, Inc. - Long-Term Project Reporting
}

\section{Note: This example illustrates only one approach to analyzing a project; your analysis, methods, and calculations will vary depending on your particular circumstances, the geographic location of the project, and other factors.}

Black Forest Cake, Inc. (BFCI) was a family-owned business that was experiencing extremely rapid growth in demand for its products, which included baked goods produced at 13 sites in five states, catering services at 10 shops in seven states, and equipment rentals at 15 stores in three states. It operated from a total of 23 sites spread across nine states.

The family members and many of their staff were environmentally conscious. While they were delighted with the increased demand for their products, they were concerned to see their energy consumption rising, particularly their nanural gas consumption for baking ovens and space heating, and their gasoline use in delivery vehicles. They knew that increased energy use signaled increased greenhouse gas emissions.

Therefore, BFCI decided to voluntarily offset some of the increase in emissions by undertaking a tree-planting (carbon sequestration) project on farmland they owned. They were not interested in receiving official recognition for their effort. They were motivated purely by their interest in environmental protection and a desire to project an image of BFCI as a "good global citizen." They did, however, want to be sure that their project actually reduced net carbon dioxide emissions, not just appear to do so. Therefore, BPCI decided that its project should at least meet the minimum reporting standards used by DOE in the EPAct $1605(\mathrm{~b})$ voluntary greenhouse gas reporting program.

In its first report following the establishment of the tree stand, BFCI reported that it had planted the trees and reported information consistent with the guidance provided in the forestry sector supporting document. It also reported that it expected the forest to capture carbon at a rate consistent with the stipulated factors provided by the guidelines' supporting document for forestry. Each year thereafter BFCI confirmed in its report that the project appeared to continue to perform as expected.

After eight years of relying on the default stipulated factors, BFCl became engaged in a dialogue with a local environmental group. One consequence of the discussions was that BFCI agreed to measure the standing carbon on its project site in the tenth year to determine whether the project had met the expectations established for the first decade by the stipulated factors. The field measurements, including statistical sampling of both soils and biomass, revealed that the project had actually exceeded expectations by 20 percent. This was attributed to the fact that the original soils were particularly rich in phosphorous and nitrogen.

BFCI amended its previous reports to reflect this new information based on field measurements. The amended reports increased the reported carbon dioxide flows to the forestland by 20 percent in each of the first ten years. BPCI also amended the projected annual carbon capture rates for the second decade to reflect the higher-than-expected performance. BFCI thus transformed its project from a standard project to a reporter-defined project.

\section{GG-6 What Are the Minimum Reporting Requirements?}

DOE has not established a minimum size for a reporting entity or for the reported emissions, emissions reduction, or sequestered carbon. For some purposes of reporting, such as the exchange of informa-

\author{
General Guidelines-Page 25
}


tion on pilot projects, a minimum size requirement would limit participation. Similarly, you are not required to complete a full and comprehensive report as defined earlier. However, you must report a minimum set of information.

Whatever the scope of your report, you are required to certify the accuracy of the data you have provided. You must also meet minimum information requirements:

- If you are reporting greenhouse gas emissions, you must clearly identify the facilities that are covered by your report and, for each greenhouse gas covered by your report, clearly identify the gas, the amount of the emissions (expressed in metric tons of that gas per year), and the year of the emissions.

- If you are reporting emissions reductions or carbon sequestration projects, you must be able to describe your project and provide sufficient physical data to allow users of the database to form a clear understanding of the nature and scope of your project, inciuding the cause of the change in emissions or carbon sequestration. You must also identify the location of the project, the reference case for the project, and the effects of the project.

- Whether you are reporting on a standard project or a reporter-designed project, you must be able to identify the sources of your data, the level of change of emissions or carbon sequestration per year, and the year in which the change took place.

- If you are submitting a reporter-designed project report involving direct monitoring and measuring or engineering estimations, you must also identify the techniques used to gather the data and make the estimates.

\section{GG-7 Can My Data Be Kept Confidential?}

The provisions of Section 1605(b)(3) stipulate that "Trade secret and commercial information that is privileged or confidential shall be protected as provided under Section 552(b)(4) of Title 5, United States Code." In general, information submitted to the Federal government must be made available to the public. This section prohibits release of certain trade secret and commercial or financial information.

You will enhance both the credibility and usefulness of information you report by making it available for public release. More accurate data will increase the value of emissions reductions estimates in terms of public recognition, and widely available information will help diffuse knowledge about costeffective emissions reductions opportunities. Thus, you should try to avoid labeling reported information as confidential wherever possible.

While a reporter may believe that some of the data voluntarily submitted under this program is entitled to protection under the exclusion, this protection is neither automatic nor complete. You should be 
aware that, under DOE regulations (10 CFR 1004.11), DOE will evaluate each claim of confidentiality and determine whether or not to disclose the data to the public. Also, data may be released to another Federal agency under certain circumstances regardless of any claim of confidentiality.

\section{GG-8 What Certification Is Required?}

If you report under this program, you will be required to certify through your signature the accuracy of all the information reported. Therefore, the person who signs the report must be authorized to act as a representative of the reporting entity for these purposes. No independent certification is required, and the Federal government does not plan to certify your reports. However, you may wish to indicate if your data have been verified by a third party.

\section{GG-9 What Should I Do Next?}

These general guidelines present an overall picture of the reporting process for the voluntary reporting program. You will find more detailed guidance in the sectoral supporting documents for electricity supply, residential and commercial buildings, industry, transportation, forestry, and agriculture. You may have reportable projects in several sectors; you may report them separately or capture and report the total effects on an entity-wide report. If you need the supporting documents, contact United States Department of Energy, 1000 Independence Avenue, S.W., Washington, DC 20585.

Reporting forms are available at the following address: United States Department of Energy, Energy Information Administration, 1000 Independence Avenue, S.W., Washington, DC 20585.

DOE encourages you to report your achievements in reducing greenhouse gas emissions and sequestering carbon under this program. Global climate change is increasingly being recognized as a threat that individuals and organizations can take action against. If you are among those taking action, reporting your projects may lead to recognition for you, motivation for others, and synergistic learning for the global community. 